\title{
Ethical climate in a Belgian psychiatric inpatient setting: relation with burnout and engagement in psychiatric nurses
}

\author{
Astrid Faelens RN MSc ${ }^{a}$, Marleen Claeys RN MSc ${ }^{b}$, Bernard Sabbe MD PhD ${ }^{c}$, Didier \\ Schrijvers MD PhD ${ }^{d}$ and Patrick Luyten $\mathrm{PhD}^{\mathrm{e}}$
}

\author{
a University Psychiatric Centre, University Hospital Leuven, Belgium \\ b Psychiatric Hospital Sint-Norbertushuis, Duffel, Belgium \\ c Head of the Department of Psychiatry, Psychiatric Hospital Sint-Norbertushuis, Duffel and Coordinator, Collaborative \\ Antwerp Psychiatric Research Institute (CAPRI), University of Antwerp, Faculty of Medicine and Health Sciences, Antwerp, \\ Belgium \\ d Psychiatric Hospital Sint-Norbertushuis, Duffel and Collaborative Antwerp Psychiatric Research Institute (CAPRI), \\ University of Antwerp, Faculty of Medicine and Health Sciences, Antwerp, Belgium \\ e Professor of Clinical Psychology, Faculty of Psychology and Educational Sciences, University of Leuven, Belgium and \\ Senior Lecturer Research Department of Clinical, Educational and Health Psychology, University College London, UK
}

\begin{abstract}
Research suggests a relation between the ethical climate - that is, the organisational conditions and practices that affect the way ethical issues with regard to patient care are discussed and decided - and job satisfaction of nurses. Yet no study to date has investigated the relationship between ethical climate and job satisfaction in psychiatric nurses. This study aimed to address this critical gap in our knowledge by investigating the relationships among ethical climate and features of both burnout and engagement based on the Job Demands-Resources Model (JD - R model) in a large cross-sectional study of 265 nurses working in a large psychiatric inpatient hospital in Flanders, Belgium. Correlational and multiple hierarchical regression analyses were used to investigate the relationship between ethical climate, burnout and engagement. In addition, based on the JD-R model, we also investigated whether engagement mediated the relationship between ethical climate on the one hand and job satisfaction and turnover intention on the other and whether ethical climate moderated the relationship between emotional burden and burnout. Results showed that a positive ethical climate was related to lower levels of emotional exhaustion and distancing and higher levels of engagement and job satisfaction. Furthermore, although ethical climate did not buffer against the effects of emotional burden on burnout, higher levels of engagement explained in part the relationship between ethical climate and job satisfaction.
\end{abstract}

\section{Keywords}

Burnout, engagement, ethical climate, job wellbeing, mental healthcare, nursing, person-centered healthcare

\section{Correspondence address}

Ms. Astrid Faelens, Lindebaan 14, 3300 Tienen, Belgium. E-mail: astridfaelens@hotmail.com

Accepted for publication: 7 February 2013

\section{Introduction}

Psychiatric nurses are continuously confronted with ethical problems and dilemmas in their work setting. Several authors have suggested that the constant confrontation with ethical issues and dilemmas may have an important impact on psychiatric nurses' job satisfaction [1,2]. Psychiatric nurses are on a daily basis confronted with ethical issues related to the lack of privacy of patients, medication compliance or personal hygiene, but also more complex ethical issues such as forced hospitalizations or questions about euthanasia, which is legalized under certain circumstances in some countries such as Belgium. In this context, the ethical climate of an organization appears to be an important but often underestimated factor. The ethical climate of a healthcare organization can be defined as 'the organisational conditions and practices that affect the way difficult patient problems, with ethical implications, are discussed and decided' [3]. Indeed, the ethical issues that nurses are confronted with demand a complex and dynamic process of negotiating that is situated within the specific organizational context of the work setting $[4,5]$.

Previous research in general hospital settings has found that a supportive ethical climate is positively related to job satisfaction and negatively related to turnover intention among nurses [3,6]. Hart, for instance, reported the ethical climate in acute care hospitals to be the most important variable predicting turnover intention, staffing, work load and feelings of autonomy in a study of 463 registered nurses [3]. Ulrich et al. also found that ethical climate was a significant predictor of job satisfaction and 
turnover intention in a sample of 1215 nurses and social workers [6].

Yet, to date, no study has investigated the role of ethical climate in the context of psychiatric nursing. Results from studies in general hospital settings do not necessarily generalize to psychiatric nurses. For example, in psychiatric care there seems to be a greater involvement of multiple professional disciplines in teams and decisionmaking. The current study therefore aims to investigate whether the ethical climate in a psychiatric center is related to the job wellbeing of psychiatric nurses based on the well-known Job Demands-Resources Model [7] (see Figure 1) in a large psychiatric hospital in Flanders, Belgium. First, the JD-R model is presented in the context of the putative role of the ethical climate in a psychiatric nursing context. Next, the aims of the present study are outlined.

\section{Figure $1 \mathrm{~J}$ ob Demands - Resources Model (Based on [7])}

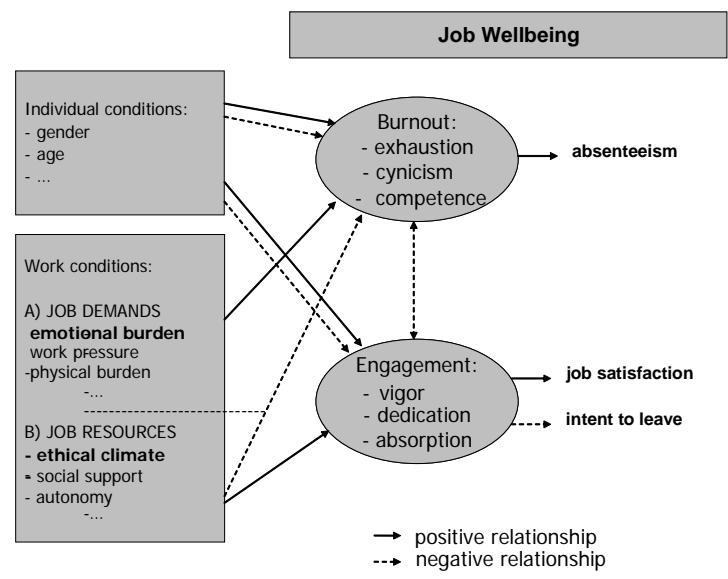

The JD-R model essentially proposes that, aside from personal characteristics, job-related features also influence job wellbeing and actually may be even more important. The ethical climate of an organization may be a key jobrelated feature.

Specifically, the first assumption of the JD-R model is that every work environment has specific work characteristics, such as task demands, job pressure and emotional challenges. Second, every work context also is characterized by specific resources such as autonomy, feedback or social support [8]. According to the JD-R model, both have an influence on job wellbeing. More specifically, job demands and resources are presumed to predict burnout and engagement, which in turn are considered to be important indicators of job satisfaction.

The concept of burnout is thought to consist of 3 features, that is, (a) emotional exhaustion, (b) depersonalization/cynicism and (c) feelings of diminished personal accomplishment due to burdening factors in the work environment [9]. Psychiatric nurses with burnout can feel physically and mentally drained, have cynical attitudes towards patients and feel inferior in their job [10]. Engagement, by contrast, is defined as a positive, fulfilling, work-related state of mind that is characterized by vigour, dedication and absorption. Engaged psychiatric nurses are typically full of energy, experience their job as inspiring and challenging and deal with difficult aspects of their tasks in an optimistic way [11].

To summarize, the JD-R model proposes that continuous exposure to high task demands can negatively affect employees energy levels, resulting in exhaustion and finally full-blown burnout. This subsequently will result in high turnover intention and absenteeism. On the other hand, job resources are related to engagement and stimulate the motivation of employees [11]. This can result in positive effects such as greater job satisfaction and low turnover intention. A lack of job resources may therefore result in less effective coping with task demands and a more distancing attitude towards work in general, which may eventually result in burnout. Hence, job resources thus may have a buffering role, buffering the effects of task demands.

Currently, there are no studies that have investigated the relationship between ethical climate and features of burnout and engagement in psychiatric nurses. Therefore, levels of emotional burden, burnout and engagement were first compared with normative samples of employees in the general population and in healthcare more specifically [e.g., 12-14].

Second, it was hypothesized, based on the research reviewed above and the JD-R model, that a supportive ethical climate would be positively related to engagement and job satisfaction and negatively related to burnout, turnover intention and absenteeism.

Third, taking into account that a positive ethical climate may be an important job-related resource and thus may play a buffering role in coping with emotionally demanding tasks, it was hypothesized that a positive ethical climate, as reported by psychiatric nurses, moderated the relation between emotional burden and burnout.

Finally, it was investigated whether engagement mediated the effects of ethical climate on job satisfaction and turnover intention. Specifically, a more positive ethical climate was expected to lead to higher levels of engagement, which in turn were expected to predict higher levels of job satisfaction and lower levels of turnover intention. Hence, higher levels of engagement were expected, at least in part, to explain the relationship between ethical climate and job satisfaction/turnover intention.

\section{Methods}

\section{Design}

This study is part of a broader study concerning the relation between ethical climate and job wellbeing in a large sample of nurses working in a psychiatric hospital [15]. The study was approved by the ethical committee of Psychiatric Hospital Sint-Norbertushuis in Duffel, a large psychiatric inpatient setting in Flanders, Belgium, with a capacity of 600 patients. 
For this study, all 320 nurses were invited to participate in the study from June 1 to July 8 2009. The research project was presented in person by 2 of the authors on all 24 wards. Participants were reassured that all information would be treated confidentially and anonymously. Participation was voluntary and returning the questionnaire was viewed as consent to participate. To ensure participation, head nurses were contacted up to 3 times to motivate them to encourage their staff to participate and each department was visited twice and received 2 letters to encourage participation.

\section{Measurement}

All participants completed a series of questionnaires regarding socio-demographic variables: gender, marital status, age, religious beliefs, job time equivalent (whether they worked full-time or part-time), day or night work hours, number of working hours, number of years in the current position, level of education and work setting.

Work characteristics were assessed using measures concerning emotional burden and ethical climate. Ethical climate was measured by means of the Hospital Ethical Climate Survey (HECS [16]). The original HECS contains 26 questions divided over 5 dimensions: the relationship between nurses and 1) physicians, 2) managers (head nurses), 3) peers (colleagues), 4) patients and 5) hospital. Each item is scored on a 5-point Likert scale ranging from 1 (almost never true) to 5 (almost always true). Examples of items are respectively: 1) 'nurses and physicians trust one another', 2) 'my manager supports me in my decisions about patient care', 3) 'my peers help me with difficult patient care issues', 4) 'the patient's wishes are respected' and 5) 'a clear sense of the hospital's mission is shared with nurses'.

As described in detail elsewhere, the HECS has been adapted and validated for use in Flemish psychiatric hospitals [15]. As the correlations between the subscales of the HECS and the other variables were similar to correlation with total HECS scores, results were only reported for the total scores $(\alpha=0.91)$.

To measure the job demand emotional burden, the 'Vragenlijst Beleving en Beoordeling van de Arbeid' (VBBA-kern [17]) was used. This questionnaire contains 7 items with 4 response categories for each separate item (always/often/sometimes/never, scores 0-3) (e.g., Is your job emotionally difficult?). It has been shown to have good reliability ( $\alpha=0.85$ ). In order to be able to compare the results of this questionnaire with a reference sample, all scores were transformed into standardized scale scores. Cronbach's $\alpha$ in this study was 0.92 .

The concept of job wellbeing was assessed using measures of burnout, engagement, job satisfaction, turnover intention and absenteeism. Burnout was measured by means of the Utrecht Burnout Scale [13]. This scale contains 20 items divided over 3 dimensions, that is, emotional exhaustion, depersonalization/cynicism and personal competence. Items are scored on a 7-point Likert scale, ranging from 0 (never) to 6 (always). Internal consistency of the 3 scales are typically always above 0.70 .
In this study, Cronbach $\alpha$ 's were $0.84,0.65$ and 0.81 respectively.

Engagement was measured using the short version of the Utrecht Engagement Scale [18], with 9 items each for 3 dimensions (vigor, dedication and absorption). Items are scored on a 7-point Likert scale going from 0 (never) to 6 (always). In the present study the short version of the questionnaire was used and the total score was used in all analyses. Internal consistency was $\alpha=0.70$ in a study of Schaufeli and Bakker [18]. In this study, Cronbach's $\alpha$ was 0.89 .

Congruent with other studies in this area, job satisfaction was measured using one item [19]. Participants rated the extent to which they disagreed or agreed with the statement 'In general I am happy with my job' using a 4point Likert scale from 0 (totally disagree) to 3 (totally agree). The item job satisfaction assessed the extent to which 'one feels good in his/her job' and is considered to be a subjective indicator of the quality of labor in the working population [20].

The item 'I sometimes think about a job change' was used to estimate turnover intention, with 4 response options ranging from 0 (totally disagree) to 3 (totally agree).

Absenteeism was measured by self-report using the following item: 'The past months I have been absent ... days due to illness'.

\section{Statistical analysis}

First, the level of emotional burden, burnout and engagement was compared with existing studies applying $\chi^{2}$-, t- en z-tests, as appropriate. Second, it was investigated whether a supportive ethical climate was positively related to engagement and job satisfaction and negatively related to burnout, turnover intention and absenteeism, using Pearson correlation coefficients. Third, Hierarchical Multiple Regression Analyses (HMRAs) were used to test for moderation effects. Four HMRAs were run with the 3 burnout dimensions (emotional exhaustion, depersonalisation and personal competence) and engagement as dependent variables. For these analyses, the independent variables 'ethical climate' and 'emotional burden' were centered [21] and the interaction terms were calculated based on the product of both centered variables for the testing of the interaction effects. Sociodemographical factors that correlated with any of the burnout dimensions or engagement were entered in a first block. In a second block, work characteristics, that is, ethical climate and emotional burden, were entered. Next, interaction terms (i.e., the product of ethical climate and emotional burden) were entered to test for moderation effects. Changes in $\mathrm{R}^{2}$ were used to test the significance of variables in each block.

Finally, to investigate whether engagement mediated the relationship between ethical climate on the one hand and job satisfaction and turnover intention on the other, a series of regression analyses was run using criteria outlined by Baron and Kenny [22]. Within this framework, 3 conditions have to be fulfilled for mediation: (a) the independent variable (e.g., ethical climate) has to correlate 
with the dependent variable (e.g., job satisfaction and turnover intention), (b) the independent variable (e.g., ethical climate) must correlate significantly with the supposed mediator variable (e.g., engagement) and (c) the purported mediator engagement has to correlate significantly with the dependent variables job satisfaction and turnover intention. The Sobel test was used to test for the significance of the mediation effect. All analyses were done using SPSS version 16 (SPSS Inc. ${ }^{\circledR}$ ).

\section{Results}

\section{Descriptive analyses}

In total, 320 nurses were asked to participate in the study of which 265 completed the questionnaire (response rate of $83 \%$ ). Their mean age was 40.7 (SD = 9.7; range 22 - 62), with most nurses being female (85.6\%). In terms of age, the largest group consisted of participants aged 41 to 50 (42.3\%) and the majority of participants were married or living together (75\%). Most of the participants worked full-time (51.8\%), during day hours (80.5\%), longer than 20 years $(44.4 \%)$ and with a maximum of 5 years on their present ward (38.8\%). Regarding the type of ward, $21.2 \%$ worked on a medium term treatment ward (hospitalization of max 6 months), $42.2 \%$ on a long term (hospitalization > 6 months) and $36.8 \%$ on a short term treatment ward (hospitalization of max 3 months).

The mean score for emotional burden was 41.67 (SD = 10.88), which was significantly higher compared to the Flemish working population $(\mathrm{M}=26.8, \mathrm{SD}=17.1 ; \mathrm{z}=$ 8.696; $\mathrm{p}<0.001$ ) [12]. Moreover, in the latter study, employees were subdivided in 3 categories of emotional burden, that is, 'not problematic', 'problematic' and 'acutely problematic'. In the current study, $47 \%$ belonged to the problematic category, compared with only $16 \%$ of Flemish employees from the general population and 30\% of the employees in the health sector [12]. Scores in the current study were also higher than these from participants from the health sector [12] $\left(\chi^{2}=36, \mathrm{p}<0.000\right)$.

For burnout, there were no data for Belgium, so data were used from a study in The Netherlands (which is not only a neighboring country, but also very similar to Belgium in terms of cultural and socio-economic features) in a group of employees from general healthcare, police and justice and mental healthcare [13]. Compared to these groups, psychiatric nurses in this study reported less feelings of exhaustion $(\mathrm{z}=-8.83, \mathrm{p}<0.001$ and $\mathrm{z}=-9.65$, $\mathrm{p}<0.001$, respectively), but also less personal competence $(\mathrm{z}=-2.02, \mathrm{p}<0.05$ and $\mathrm{z}=-11.39, \mathrm{p}<0.001)$. The mean score for engagement was 4.03 ( $\mathrm{SD}=0.92$ ), which is significantly higher than the mean score of 3.74 in the working population from The Netherlands $(\mathrm{SD}=1.17$; $\mathrm{z}=$ 2.48, $\mathrm{p}=0.013$ ) [14]. In the current study, $86 \%$ appeared to be 'often' or 'always' proud of his/her job, $84 \%$ appeared to be enthusiastic about his/her job and 70\% reported being 'full of energy' during his/her work.

Finally, concerning job satisfaction, $58 \%$ of the participants agreed with the statement: 'in general, I am happy with my job' and 40\% completely agreed with it. Forty-two percent did not have any turnover intention and the mean number of self-reported absenteeism days was $5.66(\mathrm{SD}=17.84$; range 0 - 180 days $)$.

\section{Correlational analyses}

Table 1 presents the zero-order correlations between the study variables and means and standard deviations.

In line with expectations, emotional burden was positively correlated with emotional exhaustion, depersonalization / cynicism and turnover intention. Engagement was positively related to job satisfaction and negatively to turnover intention. Absenteeism did not correlate with any of the variables.

As expected, a positive ethical climate was negatively correlated with emotional exhaustion, depersonalization and turnover intention. Also, a better ethical climate was positively correlated with personal competence, engagement and job satisfaction.

Somewhat surprisingly, emotional burden, competence and engagement correlated positively. Although significantly correlated, these correlations were very small. Furthermore, there was no correlation between ethical climate and emotional burden (see Table 1).

\section{Regression analyses}

Based on bivariate analyses (t-tests), gender and working in day or night shift were significant predictors of burnout dimensions (Block 1). Yet only working in day or night shift remained a significant predictor for the 3 burnout dimensions when inserting emotional burden in the analysis in Block 2. When inserting ethical climate independent from emotional burden in Block 2, only working in day or night shift remained significant in explaining emotional exhaustion and depersonalization. None of the socio-demographic variables were significant predictors of engagement.

In Block 2, ethical climate contributed significantly to the explained variance of emotional exhaustion, depersonalization and personal competence, in addition to the socio-demographical characteristics, explaining an additional $2.8 \%, 6.4$ and $9.7 \%$ of the variance, respectively. Ethical climate also was a significant predictor of engagement, adding almost $12 \%$ to the explained variance.

In Block 3, ethical climate and emotional burden contributed uniquely to the prediction of emotional exhaustion, depersonalization, personal competence and engagement (all $\mathrm{p}<0.001$ ), even when controlling for variables in Block 1. Both work characteristics together explain $12.4 \%$ of the variance in emotional exhaustion, $9.7 \%$ of the variance in depersonalization, $12.2 \%$ of the variance in personal competence and $14.1 \%$ of the variance in engagement.

In Block 4, none of the interaction effects was significant. Therefore, it can be concluded that ethical climate does not buffer against the effects of emotional burden. 
Table 1 Description of measurement instruments and correlations

\begin{tabular}{|c|c|c|c|c|c|c|c|c|c|c|c|}
\hline Scale (scoring) & 1 & 2 & 3 & 4 & 5 & 6 & 7 & 8 & $\mathbf{N}$ & Mean (SD) & Cr. A \\
\hline $\begin{array}{l}\text { 1. Emotional } \\
\text { burden }(0-3)\end{array}$ & & & & & & & & & 262 & $2.25(0.33)$ & 0.66 \\
\hline $\begin{array}{l}\text { 2. Ethical Climate } \\
(1-5)\end{array}$ & -0.072 & & & & & & & & 264 & $3.85(0.46)$ & 0.92 \\
\hline 3. Burnout EE (0-6) & $0.336^{\star \star}$ & $-0.145^{\star}$ & & & & & & & 259 & $1.24(0.73)$ & 0.84 \\
\hline 4. Burnout C (0-6) & $0.206^{\star *}$ & $-0.231^{\star *}$ & $0.545^{\star *}$ & & & & & & 259 & $\begin{array}{l}\text { M: } 1.06(0.74) \\
F: 0.80(0.56)\end{array}$ & 0.65 \\
\hline 5. Burnout PC (0-6) & $0.139^{*}$ & $0.326^{\star *}$ & -0.118 & $-0.211 * *$ & & & & & 259 & $4.11(0.75)$ & 0.81 \\
\hline $\begin{array}{l}\text { 6. Engagement } \\
(0-6)\end{array}$ & $0.133^{*}$ & $0.344^{\star *}$ & $\underset{\star \star}{-0.247}$ & -0.255 ** & $0.741^{\star \star}$ & & & & 255 & $4.03(0.92)$ & 0.89 \\
\hline $\begin{array}{l}\text { 7. Job Satisfaction } \\
(0-3)\end{array}$ & -0.118 & $0.287^{\star \star}$ & $\underset{\star \star}{-0.381}$ & $-0.181 * *$ & $0.218^{\star \star}$ & $0.334^{\star \star}$ & & & 260 & $2.38(0.54)$ & \\
\hline $\begin{array}{l}\text { 8. Intent to leave } \\
(0-3)\end{array}$ & 0.103 & -0.113 & $0.385^{\star \star}$ & $0.228^{\star \star}$ & -0.006 & $-0.245^{\star \star}$ & $-0.285 * *$ & & 260 & $1.17(0.81)$ & \\
\hline $\begin{array}{l}\text { 9. Absenteeism } \\
\text { (days) }\end{array}$ & -0.123 & 0.027 & -0.012 & 0.003 & 0.058 & -0.001 & -0.011 & 0.056 & 251 & $5.66(17.84)$ & \\
\hline
\end{tabular}

$\mathrm{EE}=$ Emotional Exhaustion, $\mathrm{C}=$ Cynicism, $\mathrm{PC}=$ Personal Competence, $\mathrm{M}=$ male, $\mathrm{F}=$ female, ${ }^{*} \mathrm{p}<0.05,{ }^{* *} \mathrm{p}<0.01$

Table 2 Regression analysis

\begin{tabular}{|c|c|c|c|c|}
\hline & $\begin{array}{l}\text { Emotional } \\
\text { Exhaustion }\end{array}$ & $\begin{array}{l}\text { Depersonalization/ } \\
\text { Cynicism }\end{array}$ & $\begin{array}{l}\text { Personal } \\
\text { Competence }\end{array}$ & Engagement \\
\hline Block 2 & $\beta$ & $\beta$ & $\beta$ & $\beta$ \\
\hline \multicolumn{5}{|l|}{ 2a Emotional burden } \\
\hline Day-night & $-0.208^{\star \star}$ & $-0.142^{*}$ & $-0.122^{\star \star}$ & n.s. \\
\hline Emotional burden & $0.305^{\star \star *}$ & 0.200 ** & $0.139^{*}$ & $0.0133^{\star}$ \\
\hline $\mathrm{R}^{2}$ & 0.161 & 0.065 & 0.037 & 0.018 \\
\hline $\mathrm{R}^{2} \Delta$ & $0.093^{\star \star *}$ & $0.04^{\star \star}$ & $0.019^{*}$ & $0.018^{\star}$ \\
\hline \multicolumn{5}{|l|}{ 2b Ethical climate } \\
\hline Gender & n.s. & n.s. & n.s. & n.s. \\
\hline Day-night & $-0.243^{\star \star}$ & $-0.187^{\star \star}$ & n.s. & n.s. \\
\hline Ethical climate & $-0.168^{\star \star}$ & $-0.252^{\star \star \star}$ & $0.313^{\star \star \star}$ & $0.344^{\star \star \star}$ \\
\hline $\mathrm{R}^{2}$ & 0.095 & 0.089 & 0.114 & 0.119 \\
\hline $\mathrm{R}^{2} \Delta$ & $0.028^{\star \star}$ & $0.064^{\star \star \star}$ & $0.097^{\star \star \star}$ & $0.119^{\star \star \star \star}$ \\
\hline Block 3 & $\beta$ & $\beta$ & $\beta$ & $\beta$ \\
\hline Day-night & $-0.211^{\star \star \star}$ & $-0.171^{\star \star}$ & n.s. & n.s. \\
\hline Emotional burden & $0.308^{\star \star \star}$ & $0.183^{\star *}$ & $0.161^{\star *}$ & $0.151^{*}$ \\
\hline Ethical climate & $-0.151^{\star \star}$ & $-0.241^{\star \star \star}$ & $0.324^{\star \star \star}$ & $0.351^{\star \star \star}$ \\
\hline $\mathrm{R}^{2}$ & 0.171 & 0.122 & 0.140 & 0.141 \\
\hline $\mathrm{R}^{2} \Delta$ & $0.124^{\star \star *}$ & $0.097^{\star \star \star}$ & $0.122^{\star \star *}$ & $0.141^{\star \star \star}$ \\
\hline Block 4 & $\beta$ & $\beta$ & $\beta$ & \\
\hline Day-night & $-0.208^{\star \star *}$ & $-0.177^{\star \star}$ & -0.085 n.s. & \\
\hline Emotional burden & 0.231 n.s. & $0.331^{\star \star}$ & 0.236 n.s. & \\
\hline Ethical climate & -0.116 n.s. & $-0.309 \star \star \star$ & $0.289^{\star \star \star}$ & \\
\hline $\begin{array}{l}\text { Interaction emotional burden and ethical } \\
\text { climate }\end{array}$ & 0.098 n.s. & -0.187 n.s. & -0.094 n.s. & \\
\hline $\mathrm{R}^{2}$ & 0.172 & 0.129 & 0.141 & \\
\hline $\mathrm{R}^{2} \Delta$ & 0.002 n.s. & 0.007 n.s. & 0.001 n.s. & \\
\hline
\end{tabular}

$\mathrm{R}^{2}=$ explained variance, $\mathrm{R}^{2} \Delta=$ change in explained variance, ${ }^{\star} \mathrm{p}<0.05,{ }^{\star \star} \mathrm{p}<0.01,{ }^{\star \star \star} \mathrm{p}<0.001$ 


\section{Mediation analyses}

For job satisfaction, all conditions for mediation were fulfilled. However, this was not the case for turnover intention. Engagement partially mediated the relation between ethical climate and job satisfaction; contributing $6.5 \%$ of the explained variance in the relation between both factors (see Table 3). This mediation effect was significant, as shown by the Sobel test $(\mathrm{z}=4,04, \mathrm{p}<0,001)$ [23].

Table 3 Mediation of engagement

\begin{tabular}{|c|c|c|c|}
\hline & \multicolumn{3}{|c|}{ Job wellbeing } \\
\hline & $\beta$ & $\mathbf{R}^{2}$ & $R^{2} \Delta$ \\
\hline \multirow[t]{2}{*}{ Ethical climate } & $0.283^{\star \star \star}$ & & \\
\hline & & 0.080 & $0.080^{* * *}$ \\
\hline Ethical climate & $0.194^{\star \star}$ & & \\
\hline \multirow[t]{2}{*}{ Engagement } & $0.271^{\star \star \star}$ & & \\
\hline & & 0.145 & $0.065^{\star \star \star}$ \\
\hline
\end{tabular}

$\mathrm{R}^{2}=$ explained variance, $\mathrm{R}^{2} \Delta=$ change in explained variance, ${ }^{* *} p<0.01,{ }^{* \star *} p<0.001$

\section{Disc ussion}

The aim of this study was to explore the relation between hospital ethical climate and job wellbeing in psychiatric nurses. We first compared levels of emotional burden, burnout and engagement with normative samples. Next, we investigated relationships between features of burnout and engagement and work-related factors and whether ethical climate moderated the relation between emotional burden and burnout. Finally, we investigated whether engagement mediated the relationship between ethical climate and turnover intention and job satisfaction.

Emotional burden of the nurses in this study was substantially higher compared to a normative sample [12]. These findings support the assumption that working in a psychiatric hospital is associated with considerable emotional burden.

Yet, compared to a sample of employees from general healthcare, police and justice and mental healthcare from The Netherlands, nurses in the current study felt emotionally less exhausted and felt less distanced from their patients. Yet, they also felt less competent. These findings are not in line with current theories about burnout, which argue that diminished feelings of competence are related to emotional exhaustion and distancing from patients [11]. Hence, it seems that in psychiatric nurses, other factors may be responsible for diminished feelings of competence. Further research is therefore needed to replicate this finding and to further investigate potential factors that may explain these results. Yet, despite this, the results of this study largely confirm the hypothesis that a more positive ethical climate is associated with less emotional exhaustion and less distancing from patients. Moreover, a positive ethical climate was also associated with more feelings of competence, engagement and job satisfaction. Also, in line with previous studies [3,6], a positive ethical climate was negatively related to turnover intention. However, it should be noted that this difference failed to reach statistical significance $(p=0.069)$. Furthermore, no significant relationships were found between ethical climate and absenteeism.

Although ethical climate did not buffer the effects of emotional burden on burnout, higher levels of engagement explained in part the relationship between ethical climate and job satisfaction, which is in line with the findings of, for example, Ulrich et al. [6]. Hence, these findings suggest that ethical climate could be an important resource that should be included within the JD-R model.

An important limitation of the current study is its cross-sectional design, which, strictly speaking, does not allow the drawing of causal conclusions [24]. Hence, future longitudinal research is needed to investigate potential prospective relationships between ethical climate and job wellbeing. Regarding the JD-R model, the current study focused on only one task demand and only one job resource. This indicates that a large part of the model was not directly investigated. Also, the results of this study may not generalize to other psychiatric nursing settings and particularly not to other countries.

Notwithstanding these limitations, the results from the current study may have important implications from a clinical as a well as management perspective. Our findings suggest that a positive ethical climate is an important factor in fostering healthcare, as a positive ethical climate was related to higher levels of personal competence, engagement and job satisfaction and lower levels of emotional exhaustion and depersonalization/cynicism. Moreover, considerations concerning ethical climate will become increasingly important as healthcare becomes increasingly complex. Hence, a climate that facilitates communication about ethical issues, is increasingly required.

The current study also focused on the positive aspects related to work, that is, engagement and job satisfaction. Hence, from a management perspective, the findings of this study suggest that diminishing stressors such as work pressure is only one factor of many potential others to require investigation and study. A focus on positive aspects related to nursing may motivate employees and increase job satisfaction [25]. Investing in a positive ethical climate could be very important in this context, as this could lead to more engagement which in turn will motivate the whole organization [26].

\section{Acknowledgements and Conflicts of Interest}

We would like to thank the nursing staff and management of Psychiatric Centre Sint-Norbertushuis at Duffel, 
Belgium for their participation and support. The authors declare no conflicts of interest.

\section{References}

[1] Lützén, K., Cronqvist, A., Magnusson, A. \& Andersson, L. (2003). Moral stress: synthesis of a concept. Nursing Ethics 10, 312-322.

[2] Edwards, D., Burnard, P., Coyle, D., Fothergill, A. \& Hannigan, B. (2000). Stressors, moderators and stress outcomes: findings from the All-Wales Community Mental Health Nurse Study. Journal of Psychiatric and Mental Health Nursing 7, 529-537.

[3] Hart, S.E. (2005). Hospital ethical climate and registered nurses' turnover intentions. Journal of Nursing Scholarship 37, 173-177.

[4] Dierckx de Casterlé, B., Grypdonck, M., VuylstekeWauters, M. \& Janssen, P. (1997). Nursing students' responses to ethical dilemmas in nursing practice. Nursing Ethics 4, 12-27.

[5] Vogel Smith, K. (1996). Ethical decision-making by staff nurses. Nursing Ethics 3, 17-25.

[6] Ulrich, C., O’Donnell, P., Taylor, C., Farrar, A., Danis, M. \& Grady, C. (2007). Ethical climate, ethics stress, and the job satisfaction of nurses and social workers in the United States. Social Science and Medicine 65, 1708-1719. [7] Bakker, A., Schaufeli, W.B. \& Demerouti, E. (1999). Werkstressoren, energiebronnen en burnout. [Work stressors, energy sources and burnout.] In: Praktijkboek gezond werken: Integrale oplossingen voor somatische, psychische en psychosociale klachten in organisaties, (J. Winnubst, F. Schuur, S.J. Dam, eds.), pp. 65-84. Amsterdam: Elsevier.

[8] Demerouti, E., Bakker, A.B., Nachreiner, F. \& Schaufeli, W.B. (2001). The job demands-resources model of burnout. Journal of Applied Psychology 86, 499-512.

[9] Maslach, C. \& Jackson, S.E. (1986). Maslach Burnout Inventory: manuel (2nd edn.). Palo Alto: Consulting Psychologists press.

[10] Schaufeli, W.B. \& Bakker, A.B. (2004). Job demands, job resources, and their relationship with burnout and engagement: A multi-sample study. Journal of Organizational Behavior 25, 293-315.

[11] Schaufeli, W.B. \& Bakker, A.B. (2001). Werk en welbevinding. Naar een positieve benadering in de arbeidsen gezondheidspsychologie. [Work and wellbeing, to a positive approach]. Gedrag \& Organisatie 5, 229-253.

[12] Bourdeaud'hui, R. \& Vanderhaeghe, S. (2004). Informatiedossier Vlaamse Werkbaarheidsmonitor. [Information file of the Flemisch Work Monitor]. SociaalEconomische Raad van Vlaanderen.

[13] Schaufeli, W.B. \& Van Dierendonck, D. (2001). Utrechtse Burnout Schaal (UBOS). De Psycholoog 36, 912.

[14] Schaufeli, W.B. \& Bakker, A.B. (2003). UWES test manuel. Utrecht: Occupational Health Psychology Unit Utrecht University.

[15] Claeys, M., Faelens, A., Dierckx de Casterlé, B., Sabbe, B., Schrijvers, D. \& Luyten, P. (2013).
Psychometric properties of the Hospital Ethical Climate Survey: A study in psychiatric care. European Journal for Person Centered Healthcare 1 (1) 202-208.

[16] Olson, L.L. (1998). Hospital nurses' perceptions of the ethical climate of their work setting. Image. Journal of Nursing Scholarship 30, 345-349.

[17] Van Veldhoven, M. \& Meijman, T. (1994). Het meten van psychosociale arbeidsbelasting met een vragenlijst: de vragenlijst beleving en beoordeling van de arbeid (VBBA). [Measuring the psychosocial job burden with a questionnaire]. Amsterdam: Nederlands Instituut voor Arbeidsomstandigheden.

[18] Shaufeli, W.B. \& Bakker, A.B. (2004). Bevlogenheid: Een begrip gemeten. [Engagement: a measured concept]. Gedrag \& Organisatie 17, 89-112.

[19] Wanous, J.P., Reichers, A.E. \& Hudy, M.J. (1997). Overall job satisfaction: how good are single-item measures? Journal of Applied Psychology 82, 247-252.

[20] De Witte, H. (2001). Arbeidstevredenheid: een zinvol concept? [Job satisfaction: a useful concept?] Over Werk. Tijdschrift van het Steunpunt Werkgelegenheid, Arbeid en Vorming 11, 18-21.

[21] Aiken L.S. \& West S.G. (1991). Multiple Regression: Testing and interpreting interactions. Newbury Park, CA: Sage.

[22] Baron, R.M. \& Kenny, D.A. (1986). The moderatormediator variable distinction in social psychological research: Conceptual, strategic, and statistical considerations. Journal of Personality and Social Psychology 51, 1173-1182.

[23] Sobel, M.E. (1982). Asymptotic confidence intervals for indirect effects in structural equation models. In: Sociological Methodology (S. Leinhardt ed.), pp. 290-312. Washington DC: American Sociological Association.

[24] De Lange, A.H., Taris, T.W., Kompier, M.A.J., Houtman, I.L.D. \& Bongers, P.M. (2003). The Very Best of the Millenium: Longitudinal Research and the DemandControl-(Support) Model. Journal of Occupational Health Psychology 8, 282-305.

[25] Ouweneel, E., Schaufeli, W. \& LeBlanc, P. (2009). Van preventie naar amplitie: interventies voor optimaal functioneren. [From prevention to amplition: interventions for optimal functioning]. Gedrag en organisatie 22, 118135.

[26] Boot, A.M. (2006). Besmettelijkheid van bevlogenheid. [Infectivity of engagement]. Masterthesis. Rotterdam: Erasmus Universiteit. 